\title{
Investigation on the Influence Caused by Shield Tunneling: WSN Monitoring and Numerical Simulation
}

\author{
Hao Liu $\left(\mathbb{D},{ }^{1,2}\right.$ Jinjiang Shi, ${ }^{2}$ Jiasen $\mathrm{Li}^{3}$, and Chao Liu $\mathbb{D}^{3}$ \\ ${ }^{1}$ School of Traffic and Transportation, Beijing Jiaotong University, Beijing 100044, China \\ ${ }^{2}$ Jinan Rail Transit Corporation, Jinan 250101, China \\ ${ }^{3}$ School of Civil Engineering, Guangzhou University, Guangzhou 510006, China \\ Correspondence should be addressed to Hao Liu; lc08tj@hotmail.com
}

Received 29 December 2020; Revised 13 January 2021; Accepted 25 January 2021; Published 17 February 2021

Academic Editor: Ma Jianjun

Copyright ( $\odot 2021$ Hao Liu et al. This is an open access article distributed under the Creative Commons Attribution License, which permits unrestricted use, distribution, and reproduction in any medium, provided the original work is properly cited.

\begin{abstract}
Traditional monitoring techniques are faced with the problems of low acquisition frequency and easy to be affected by the construction environment during the shield tunneling, which cannot meet the actual needs of timeliness monitoring of surrounding environmental impact on shield tunnel construction. Based on this actual demand, a wireless sensor network (WSN) system was used to monitor the response of shield tunnel segments and surrounding buildings during the shield tunneling in this study. According to the result of the signal transmission test, an optimization scheme of microelectromechanical system (MEMS) sensor layout is designed to improve the monitoring efficiency of the WSN system. Through the comparative analysis of WSN system monitoring data and traditional monitoring data, it is found that, with the increasing distance between the monitoring section and the tunnel face, the convergence value of tunnel lining clearance gradually tends to be stable, and the wireless monitoring results of transverse clearance convergence of the tunnel in this section are consistent with the overall deformation trend of the convergence gauge monitoring results. This study also simulated the shield tunneling adjacent buildings using a nonlinear finite element method. A parameter sensitivity analysis of the support pressure of the excavation face and the grouting pressure at the tail of the shield is carried out. The results show that the surface settlement can be reduced by properly increasing the grouting pressure and the support pressure of the excavation face. Moreover, increasing the support pressure of the excavation face has a better inhibition effect on the settlement of the surface soil than increasing the grouting pressure.
\end{abstract}

\section{Introduction}

The shield method is widely used in the construction of urban rail transit system. During the shield tunneling, the adjacent area is inevitably disturbed, ascribing to the excavation surface support pressure and ground volume loss $[1,2]$. It is of great significance and value to investigate the influence of shield construction on adjacent areas $[3,4]$.

Huang and Wei [5] studied that a shield tunnel in a section of Shanghai subway was affected by a large number of overloads, which resulted in serious convergent deformation of the shield tunnel section and structural issues. The damaged section of the tunnel even showed bolt fracture, mass concrete falling off, and other issues. Sun et al. [6] analyzed the influence of shield construction on adjacent underground buildings, and the results showed that the shield construction would cause significant settlement of ground soil when it arrived. It is necessary to improve the advanced speed of shield construction and tail grouting and carry out secondary grouting in the overlying soil of shield construction to ensure construction safety. By considering the surface deformation and taking reasonable tunneling variables, Li et al. [7] explained the control measures of the ground deformation and settlement of buildings. Yoo and Kim et al. [8] introduced TURISK, a system that can predict ground deformation caused by tunnel excavation and evaluate the impact of excavation on adjacent buildings, and applied it to Daegu Metro Line 2. Based on the on-site monitoring data and the simulation results using finite element analysis (FEA), Mirhabibi and Soroush [9] studied the 
impact of parallel tunnel excavation on ground buildings by using subway Line 1 under construction in Shiraz and got some practical conclusions. In terms of the impact of shield construction on the structure, through three-dimensional numerical simulation of the tunnel and adjacent areas, Mroueh and Shahrour [10] obtained that if the dead weight of the building was ignored during modeling, the settlement value caused by tunnel excavation would be significantly reduced.

Total station instrument, level instrument, convergence gauge, and distributed optical fiber sensor are mostly used in the monitoring program of subway shield tunnel construction, as shown in Figure 1. The traditional monitoring measures are widely employed in the construction of shield tunnels. But the traditional way of tunnel construction monitoring is increasingly unable to meet the requirements in practice because of its high cost, nonautomation, nonrealtime property, low monitoring frequency, and limited monitoring area. It is difficult to realize full-range synchronous real-time monitoring, which makes the monitoring results difficult to reflect the health status of the structure in a timely and effective manner. Therefore, a wireless sensor network (WSN) system was developed to monitor the response of shield tunnel segments and surrounding buildings during shield tunneling in recent years $[11,12]$. At present, multiple preliminary achievements have been made in the application of wireless intelligent monitoring in structural health monitoring engineering. Straser et al. [13] first proposed the application of wireless sensor network for structural health monitoring and developed a low-cost wireless sensing unit applied to the dynamic performance monitoring test of the Alamosa Canyon Bridge. Professor Rice and Spencer [14] made some achievements in the research on WSN used for structural health monitoring such as bridges. Ayyildiz et al. [15] introduced a system for monitoring the health of reinforced concrete structural members and applied it to reinforced concrete structural columns under simulated earthquake conditions. The system can successfully detect the cracks of structural members. Wang et al. [16] applied the wireless sensor network inclination monitoring system to the shield tunnel of Shanghai metro for real-time monitoring, put forward the conversion formula applicable to the calculation of horizontal convergence value of the tunnel slice inclination value of the shield tunnel, and verified the accuracy of the conversion relation through on-site monitoring data. Bennett et al. [17] set up a WSN monitoring system including a gateway and 26 wireless sensor fulcrums in the shield tunnel of the London Metro. The system monitors the rotation deformation and cracks width of shield tunnel segments for a long time, which showed the feasibility of the wireless sensor network monitoring method in subway shield tunnel. Bennett et al. [18] developed a set of wireless sensor network monitoring systems for tunnel structure health monitoring, which summarized the monitoring data into the gateway and transmitted it to the user visual interface through the GPRS network, and then applied the system to the monitoring projects of London Underground and Prague Underground. The above measurement point layout is mainly based on the relevant algorithms and criteria theory to obtain the optimal point layout, but the use of numerical simulation and wireless sensing technology characteristics combined with engineering practice of the measuring point layout is relatively rare; based on this, this paper will put forward a flexible and efficient wireless sensor fulcrum layout scheme. To sum up, compared with the traditional monitoring method, WSN is easy to expand, intelligent, and of a high automatic degree. Sense of structure deformation based on wireless sensor network technology can achieve real-time dynamic monitoring and all-weather, automatic, remote security early warning, which can obtain the structure of the sensory information and timely grasp of the structure of the state of health. The WSN intelligent monitoring system and MEMS sensors including acquisition fulcrum, inclination sensor, and laser sensor are shown in Figure 2.

This paper aims to design an optimization scheme of MEMS sensor layout. A three-dimensional finite element model was conducted to simulate the excavation process of the tunnel using ABAQUS, taking into account the effect of the complex environments involving adjacent building. Moreover, an extensive parametric study was carried out to investigate the impact of grouting pressure and support pressure on adjacent building and ground response.

\section{Project Overview}

The site condition consists of two parts: (i) the adjacent buildings and (ii) the right-bound tunneling. During the tunneling process, the shield machine passed the adjacent buildings which is a six-story frame structure (as illustrated in Figure 3). The minimum distance between the shield body and the adjacent building was $1 \mathrm{~m}$. The shield tunnel and the adjacent building are shown in Figure 3. The building is $28 \mathrm{~m}$ in length and $15 \mathrm{~m}$ in width with a single-story height of $3 \mathrm{~m}$. The foundation of the building is a strip foundation with a depth of $2 \mathrm{~m}$, consisting of concrete square piles with a crosssectional dimension of $400 \mathrm{~mm} \times 400 \mathrm{~mm}$ and an average depth of $20 \mathrm{~m}$.

According to the site investigation, the geology of the right line tunnel contains miscellaneous fill, soft plastic silty clay, soft plastic clay, silty clay, plastic silty clay, diorite, and so on. The geotechnical layer related parameters are shown in Table 1. The interval shield tunneling of the right line with a depth of $19 \mathrm{~m}$ is in the form of circular reinforced concrete lining structure adopting the single-layer lining structure with staggered joints. The inner diameter of the lining is $5800 \mathrm{~mm}$, the outer diameter is $6400 \mathrm{~mm}$, and the lining thickness is $300 \mathrm{~mm}$.

\section{Monitoring Program}

The shield tunneling has a certain impact on the adjacent buildings, ground, and other structures. It is necessary to monitor buildings and surface ground in the adjacent area periodically. The MEMS sensor including laser sensors and inclination sensors was applied in this monitoring program, and the WSN system was used to transmit monitoring data. During the shield tunneling, the laser sensors and 


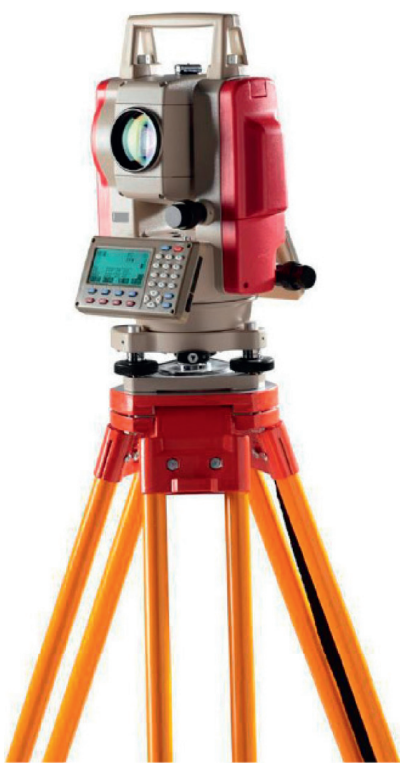

(a)
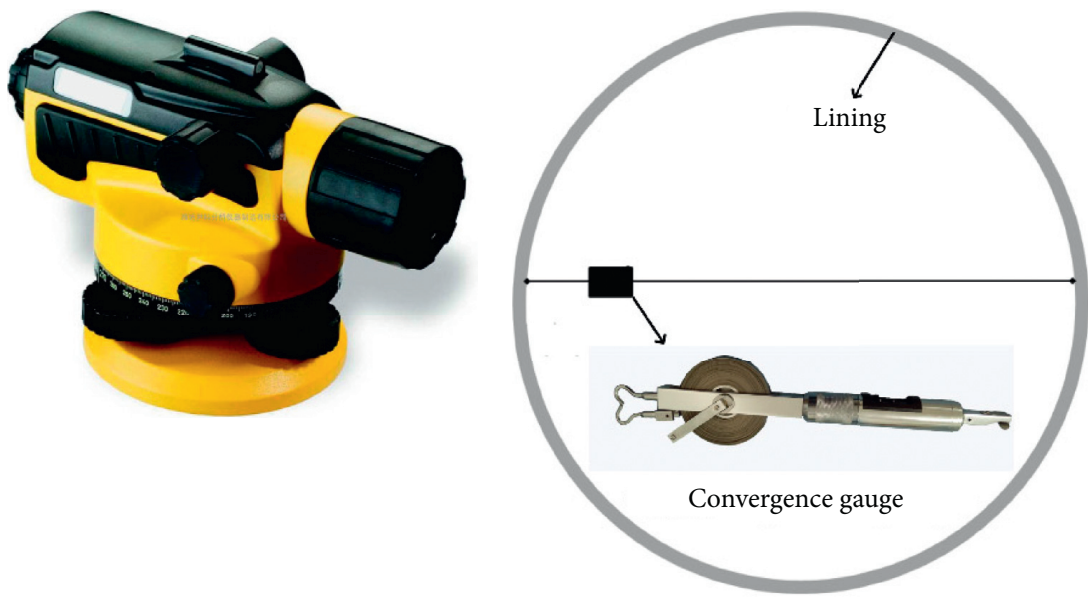

(b)

(c)

FIgURE 1: Traditional construction monitoring methods: (a) total station instrument, (b) level instrument, and (c) convergence gauge.
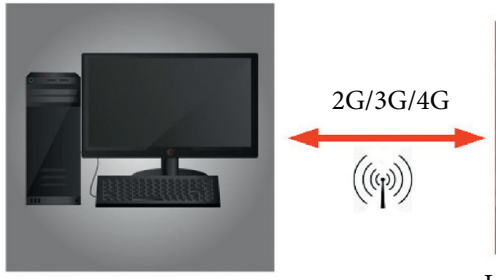

Visualization platform

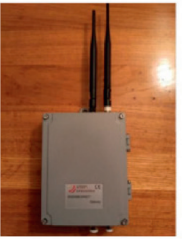

Intelligent terminal
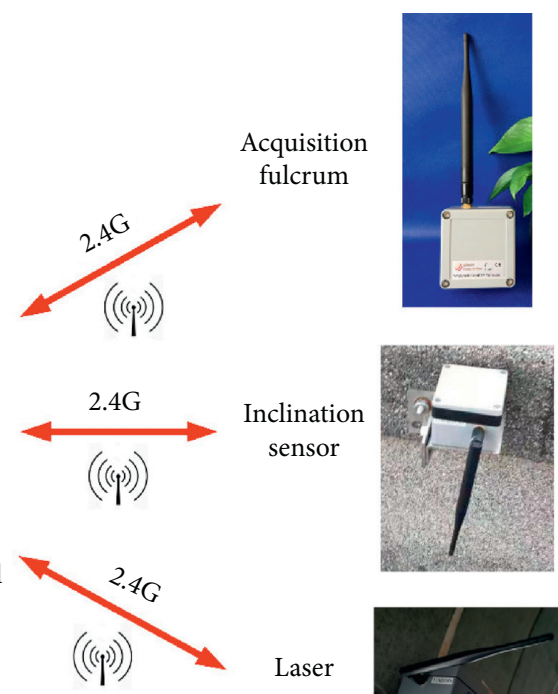

Laser

sensor

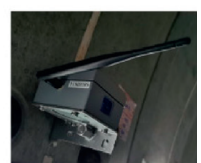

FIGURE 2: The MEMS sensors and schematic diagram of WSN.

convergence gauges were applied to monitoring the transverse clearance convergence of the lining. Moreover, the inclination sensors and total station were applied to monitoring the inclination of the adjacent building. The arrangement of monitoring points shall be followed in the following principles: (i) The layout of wireless monitoring points is designed first, followed by its details. Combined with the results of numerical simulation and engineering practice, the location of measuring points is comprehensively considered. (ii) According to the actual project, the location and quantity of wireless measuring points should be adjusted appropriately. (iii) The monitoring target should be adjusted according to the actual change of the project.

According to the experience of measuring point layout in shield construction and the actual engineering, the wireless measuring point layout of shield construction tunnel and adjacent buildings is carried out. Generally, a monitoring section is employed every 20 rings during shield construction. However, when there is an obvious deformation area, it is necessary to conduct one monitoring section of the transverse clearance convergence of the lining, and it is arranged every 8 rings of the lining in this area. The laser 


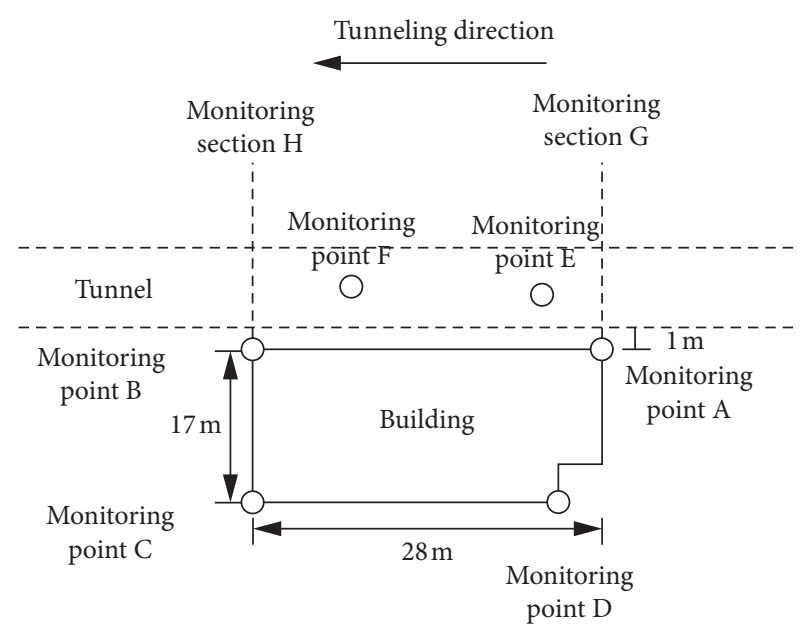

Figure 3: Layout of the site.

sensing fulcrum is arranged in the tunnel for the real-time monitoring of the lateral clearance convergence of the lining. The distance between the laser sensing fulcrum in the tunnel is about $90 \mathrm{~m}$, and the nearest is about $20 \mathrm{~m}$. The signal transmission distance between the first layer relay jump fulcrum and the intelligent terminal is about $100 \mathrm{~m}$. The layout of field measuring points is shown in Figure 4. Four inclination sensors are arranged at the four corners of the roof. The site layout is shown in Figure 4, and the plane layout of measuring points in the tunnel lining and roof is shown in Figure 5. The detailed layout information of monitoring points of the tunnel and adjacent buildings passing through the section is shown in Table 2.

\section{Analysis of Monitoring Data}

4.1. Lining Clearance Convergence. Figure 6 shows the comparison between the results of wireless monitoring and convergence meter monitoring of tunnel lateral clearance convergence. It should be pointed that the positive value of headroom convergence means that the tunnel transverse spacing increases, while the negative value means that the tunnel transverse spacing decreases. The results show that the convergence value of tunnel clearance tends to be stable with the increasing distance between the monitoring section and the working face. The overall deformation trend of the wireless monitoring results is consistent with that of the convergence gauges. However, the data collected by convergence gauges fluctuate more than that those collected by wireless monitoring. This is because the wireless monitoring is not manually operated and automatically collects data, while the convergence meter will be interfered with by relevant factors every time it collects data. From the data, the maximum change value is less than $2 \mathrm{~mm}$, which is much less than the safety control value of $10 \mathrm{~m}$.

4.2. Incline of Adjacent Buildings. Based on the monitoring results of the building inclination and settlement of the adjacent buildings, the influence of the shield tunnel construction on the six-story frame structure of the section is analyzed. Figure 7 shows the variation of the building tilt during shield tunnel construction with the difference of the distance between the excavation face and the monitoring section where the wireless measuring points $\mathrm{A}$ and $\mathrm{B}$ are located. It should be pointed out that a positive value indicates a tilt towards the side near the tunnel, while a negative value indicates the opposite. As can be seen from the above picture, the whole building leans towards the side of the tunnel. As the shield passed through the monitoring section where the measuring points $\mathrm{A}$ and $\mathrm{B}$ are located, the inclination of the house slows down, which is due to the squeezing of the surrounding soil when the shield moves forward. As the shield continues to move forward, the overall tilt of the adjacent buildings continues to increase. Until the slurry solidifies, the overall inclination increases slowly and gradually becomes stable. The maximum tilt rate is not more than 0.00008 , which is within the safety control value of 0.004 and belongs to the tilt change within the safety range.

\section{Finite Element Analysis Model}

5.1. Geometry and Mesh. A three-dimensional basic FE model with a dimension of $72 \mathrm{~m}$ (length) $\times 60 \mathrm{~m}$ (width) $\times$ $60 \mathrm{~m}$ (depth) was generated considering the adjacent building and the karst cavern filled with water. The dimension of the model was large enough to reduce the influence of the boundary conditions on the primary zone of stress and strain induced by the deep excavation. The bottom of the model is restrained from the displacements in all directions, while the nodes of the four vertical boundaries were set to zero displacements in a horizontal direction. A uniformly distributed gravity is applied to the whole model.

As illustrated in Figure 6, the soil mass is simulated by 92,304 elements of type C3D8R (8-node trilinear displacement and reduced integration modes). The six-story frame structure, lining, and grouting layer are simulated by 13,812 elements of C3D8I (8-node trilinear displacement and incompatible modes). In addition, 2,304 elements of type S4 (a 4-node doubly curved general-purpose shell) are employed for the struts and pillars. Uniform distribution of the initial void ratio of the soil is configured prior to the analysis.

5.2. Material Properties. The sectional view of the station and bridge is sketched in Figure 7. As shown in Figure 7, the ground mainly consists of miscellaneous fill, soft plastic silty clay, soft plastic clay, silty clay, plastic silty clay, diorite, and so on. The detailed material parameters used in the FEA are listed in Table 1. The main features of the Mohr-Coulomb constitutive model adopted for modeling are shown as follows:

(1) The material is initially isotropic.

(2) Yield behavior is influenced by the second principal stress $\left(\sigma_{2}\right)$.

(3) Materials are isotropic when hardened or softened.

(4) Generally, inelastic deformation occurs with volume deformation. 


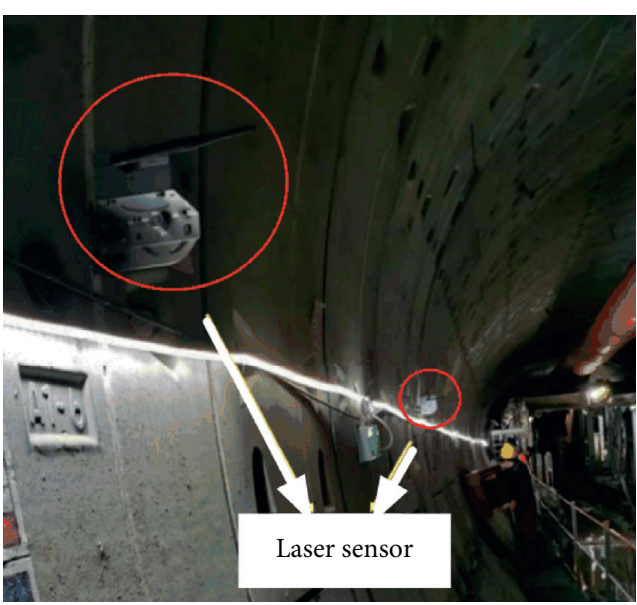

(a)

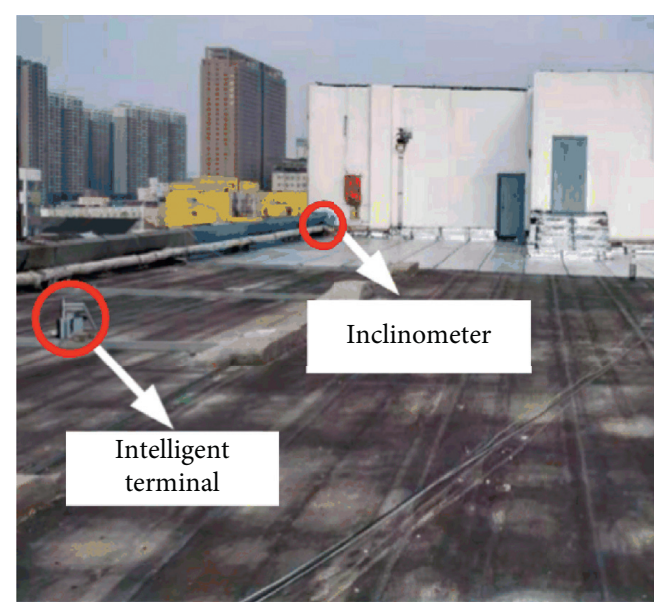

(b)

FIGURE 4: Layout of monitoring points on-site: (a) monitoring points for convergence of lining clearance and (b) monitoring points of adjacent buildings.

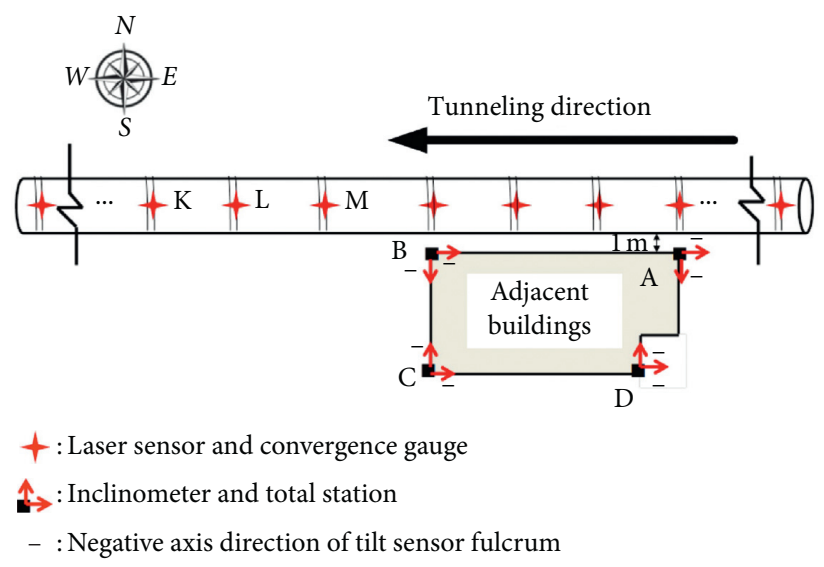

FIGURE 5: Layout of wireless sensor network (WSN) monitoring points.

TABLE 1: The main material parameters of the model.

\begin{tabular}{|c|c|c|c|c|c|c|}
\hline Soil layer & $\gamma /\left(\mathrm{kN} \cdot \mathrm{m}^{-3}\right)$ & $c / \mathrm{kPa}$ & $\varphi /^{\circ}$ & $E / \mathrm{MPa}$ & $v$ & $\mathrm{~h} / \mathrm{m}$ \\
\hline Miscellaneous fill & 19 & 10 & 15 & 19.35 & 0.35 & 4.5 \\
\hline Plasticized soft silty clay & 18.6 & 40 & 21 & 13.33 & 0.35 & 3 \\
\hline Plastic soft clay & 19.4 & 35 & 22 & 16.42 & 0.3 & 3.5 \\
\hline Silty clay & 19.6 & 36 & 22 & 17.03 & 0.3 & 3 \\
\hline Clay & 19.8 & 40 & 23 & 17.47 & 0.35 & 3 \\
\hline Plasticized silty clay & 18.8 & 45 & 22 & 17.93 & 0.3 & 5 \\
\hline Completely weathered diorite & 19.2 & 25 & 35 & 59.5 & 0.21 & 38 \\
\hline Lining & 26 & & & 36100 & 0.2 & \\
\hline Grouting layer & 20 & & & 170 & 0.3 & \\
\hline Shield shell & 27 & & & 360000 & 0.4 & \\
\hline Slab column & 24 & & & 3000000 & 0.2 & \\
\hline Pile foundation & 26 & & & 3500000 & 0.25 & \\
\hline
\end{tabular}




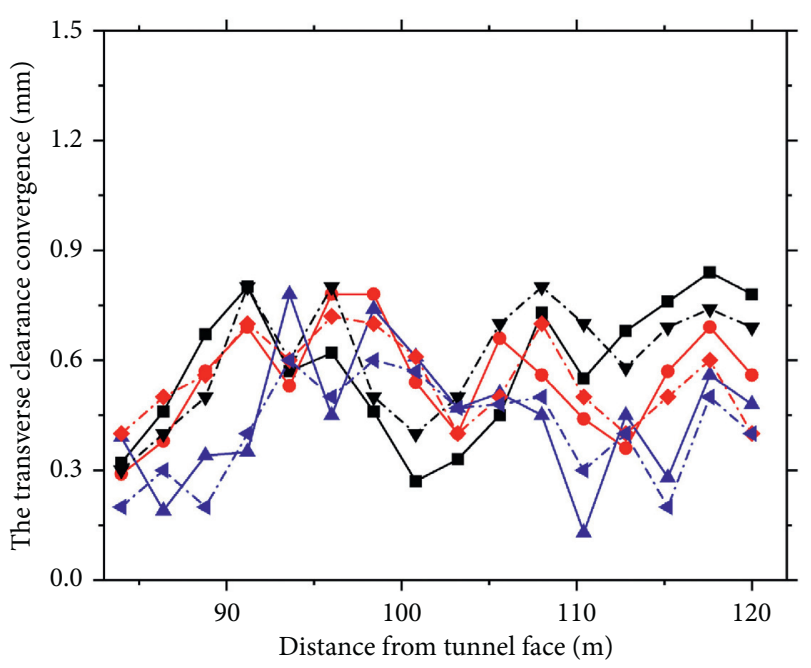

- Monitoring section $K$ (convergence gauges)
- Monitoring section $L$ (convergence gauges)
- - Monitoring section $M$ (convergence gauges)
-- Monitoring section $K$ (laser sensors)
-- Monitoring section $M$ (laser sensors)

FIGURE 6: Comparison between traditional monitoring method and WSN on tunnel lateral clearance convergence.

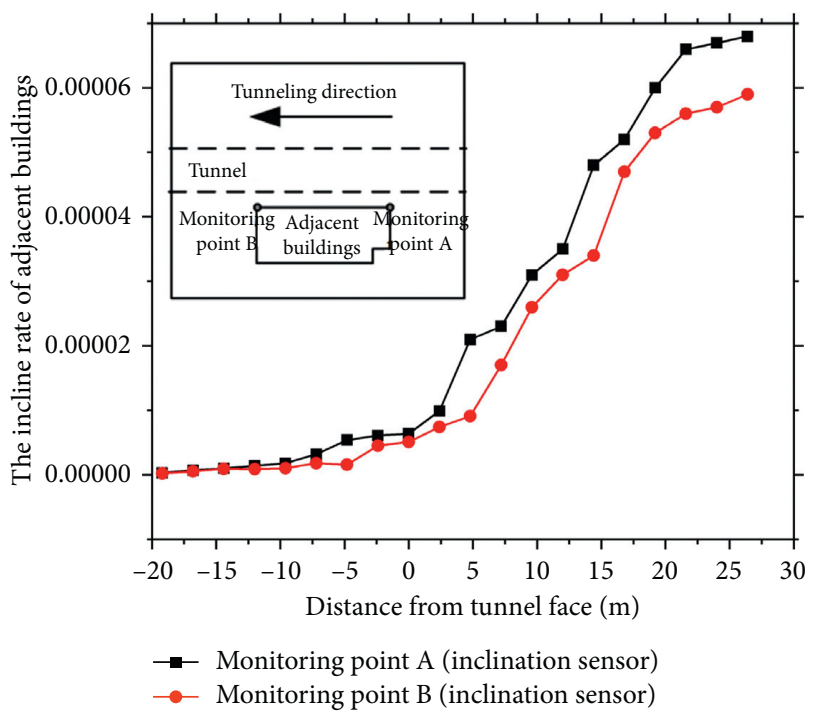

FIgURE 7: Change of inclination angle of adjacent buildings perpendicular to tunnel direction.

5.3. Simulation Procedure. The construction procedures are simulated by the "element death" technique. The speed of the construction is configured based on the field record. As shown in Figure 8, the details of the simulation process are described as follows:

Step 1. Initialization is conducted. The initial stress field of the model caused by gravity and surcharge load is configured in this step, while the initial displacement field of both is zero before the commencement of excavation.
Step 2. To simulate the tunneling of the shield machine, the 1 st ring shield machine element is deactivated and the 8th ring shield machine element is activated. Remove the support pressure in step 1 while applying the same support pressure on the excavation face. Activate the first ring lining and grouting layer, and apply uniform grouting pressure on the inner surface of the soil corresponding to the grouting layer.

Step 8. The shield unit advances 7 rings. In this process, 7 ring lining and grouting layer units are "activated." The grouting pressure is applied simultaneously to the surrounding soil elements within this range.

Step 15. The shield unit continues to advance 7 rings; at this time, the grouting pressure in step 8 is all canceled, and the corresponding grouting layer is replaced by hardened material.

\section{Discussion on Adjacent Buildings and Surface Ground}

6.1. Influence of Adjacent Buildings during Tunneling. As shown in Figure 9, measuring points A and B are two points at different positions on adjacent buildings. It is stipulated that the positive vertical displacement represents the uplift and the negative vertical displacement represents the settlement in the monitoring results. The surface settlement decreases gradually from the central axis of the tunnel to both sides, and the settlement curve is approximately symmetrical parabola shape. It is indicated that the settlement of measuring points A and point B has always occurred during tunneling. As the nearest distance between the adjacent buildings and the tunnel is $1 \mathrm{~m}$, the settlement value of the adjacent buildings is close to the surface settlement value at the axis. The settlement of adjacent buildings is within $3 \mathrm{~mm}$ and is less than $12 \mathrm{~mm}$ of the settlement control value of adjacent buildings specified in the specification [19].

6.2. Influence of Surface Ground during Tunneling. As shown in Figure 10, total station monitoring points $E$ and $\mathrm{F}$ are two surface settlement monitoring points located above the longitudinal axis of the tunnel. The vertical displacement in the numerical simulation results and the total station monitoring results is specified in this study. The positive value of vertical displacement indicates the uplift, and the negative value represents the settlement. As shown in Figure 10, through a comparative analysis of the total station results and numerical simulation, the change trend of measuring points $E$ and $\mathrm{F}$ is consistent. Due to the compression of the soil, the stress state of the soil in front of the shield tunnel changes, which leads to the settlement of the soil. When the excavation face is about $5 \mathrm{~m}$ away from the measuring point $E$, the supporting force of the excavation face increases, causing the soil mass to squeeze towards the direction of shield tunneling and thus causing a small surface uplift. Then, the supporting force of the excavation face decreases, and the soil mass settles. When the shield arrived at the section where the two measuring points were located, the surrounding soil mass changed its stress state by nearly 
TABLE 2: Monitoring scheme of shield construction affected area.

\begin{tabular}{lll}
\hline $\begin{array}{l}\text { Monitoring } \\
\text { object }\end{array}$ & $\begin{array}{l}\text { Monitored } \\
\text { parameters }\end{array}$ & $\begin{array}{l}\text { Layout scheme of monitoring points } \\
\text { points }\end{array}$ \\
\hline Adjacent & Tilting & $\begin{array}{l}\text { (1) The monitoring range is the buildings within } 30 \text { meters from the central line of } \\
\text { the tunnel } \\
\text { (2) The building displacement monitoring points are arranged on the external wall } \\
\text { or bearing column } \\
\text { (3) The distance between monitoring points along the external wall should be } \\
10 \mathrm{~m} \sim 15 \mathrm{~m} \\
\text { (4) The intelligent terminal is arranged within the visual range of } 100 \text { meters of the } \\
\text { inclination fulcrum }\end{array}$ \\
\hline Shield segment & $\begin{array}{l}\text { (1) The measuring points in the building area are arranged one for every } 8 \text { rings } \\
\text { Clearance } \\
\text { convergence }\end{array}$ & $\begin{array}{l}\text { (2) The measuring points of other sections are arranged one for every } 20 \text { rings } \\
\text { (3) One relay jump fulcrum is set every } 90 \text { meters (13 fulcrums in total), and the } \\
\text { intelligent terminal is arranged in the tunnel starting shaft }\end{array}$ \\
\hline
\end{tabular}

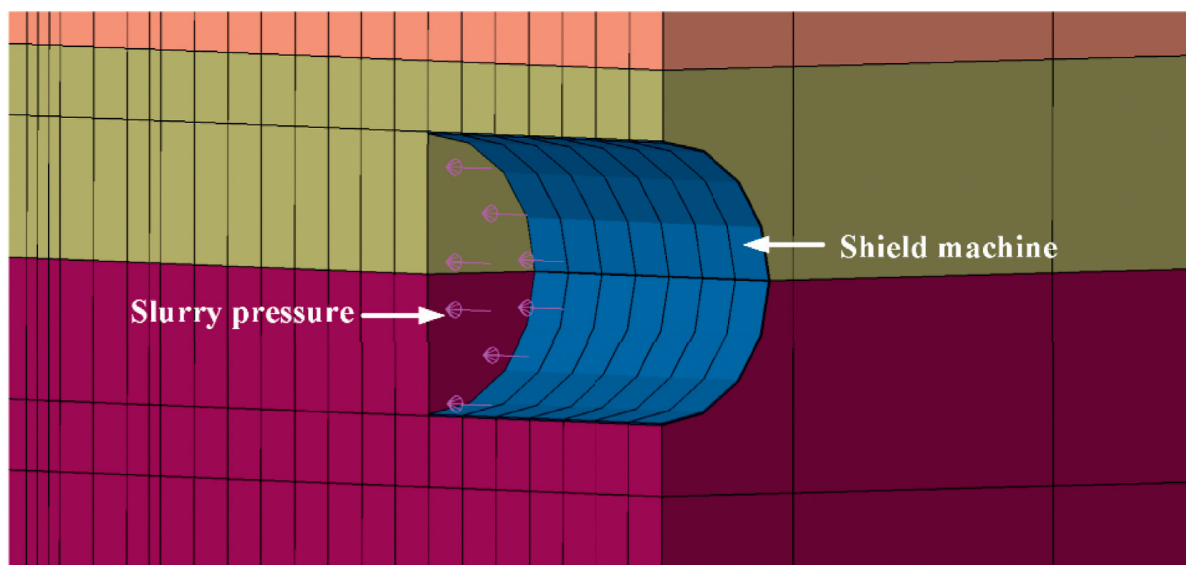

(a)

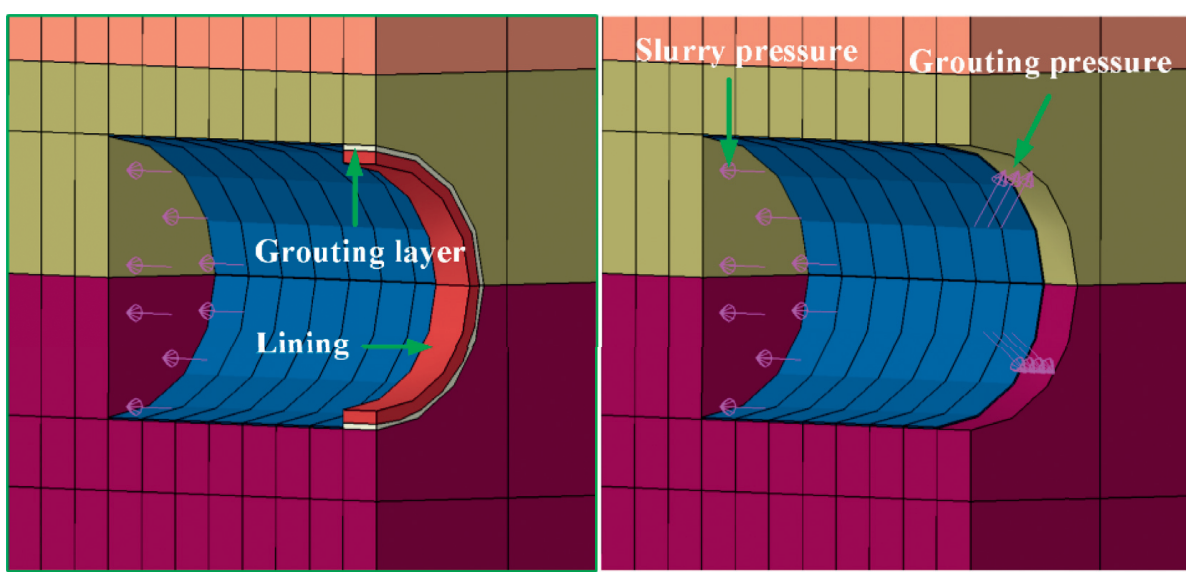

(b)

FIGURE 8: Continued. 

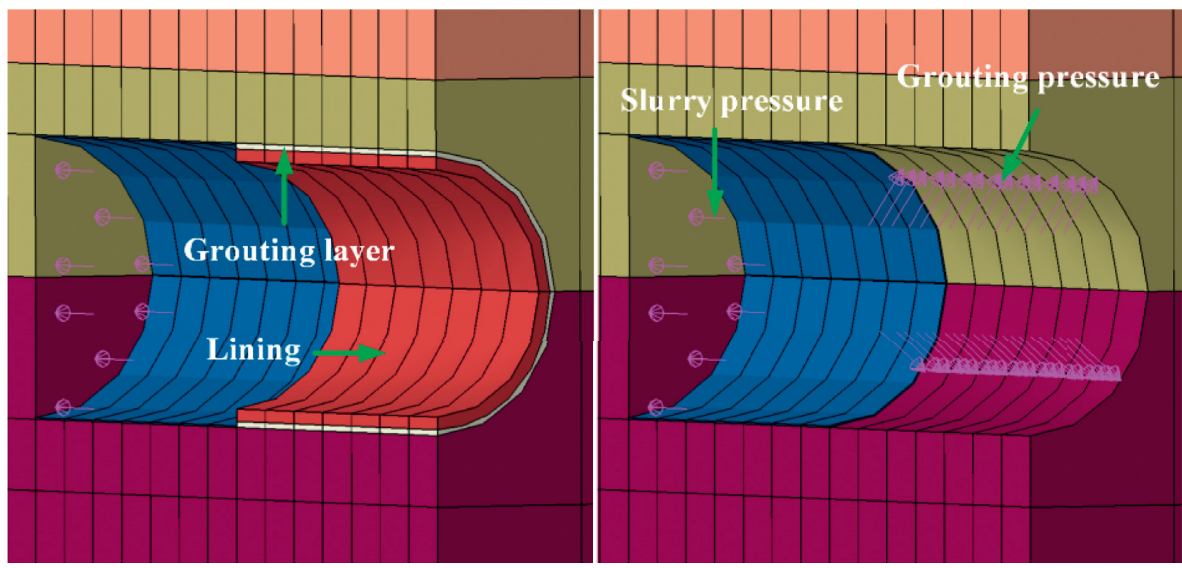

(c)

FIGURE 8: Illustration of the excavation simulation in FEA.

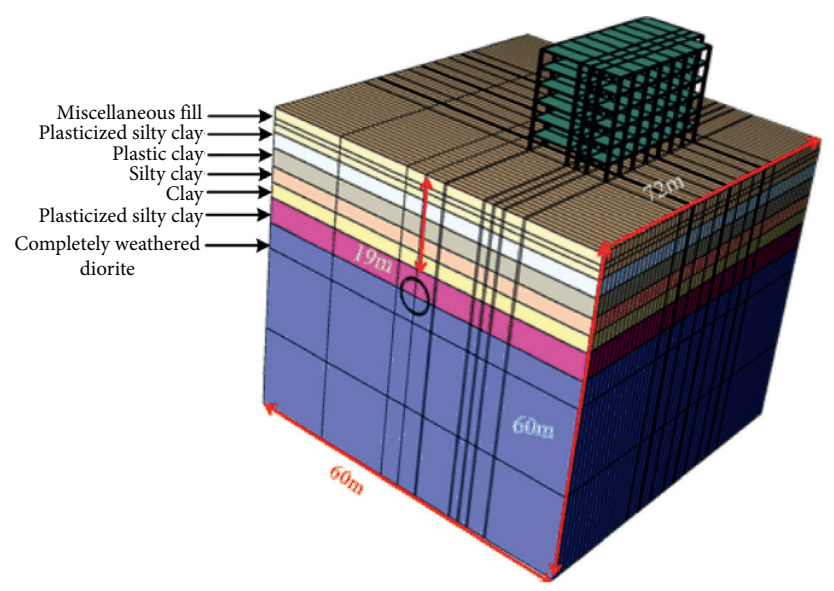

Figure 9: Three-dimensional numerical model of shield construction and its adjacent area.

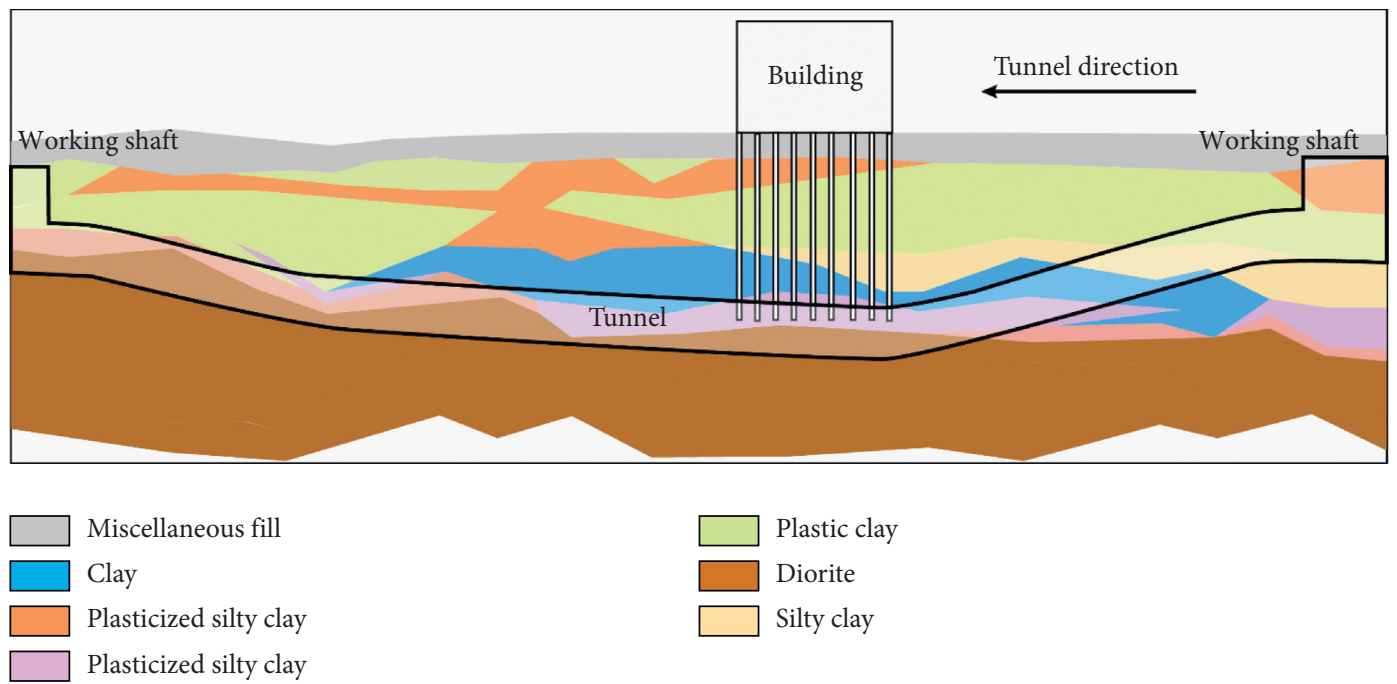

FIgURE 10: Geological profile of shield tunneling section. 
TABle 3: Parameters corresponding to different working conditions.

\begin{tabular}{lcc}
\hline Description & $K_{S}$ & $K_{G}$ \\
\hline Case 1 & 0.6 & 0.6 \\
Case 2 & 0.6 & 1 \\
Case 3 & 0.6 & 1.4 \\
Case 4 & 1 & 0.6 \\
Case 5 & 1 & 1 \\
Case 6 & 1 & 1.4 \\
Case 7 & 1.4 & 0.6 \\
Case 8 & 1.4 & 1 \\
Case 9 & 1.4 & 1.4 \\
\hline
\end{tabular}

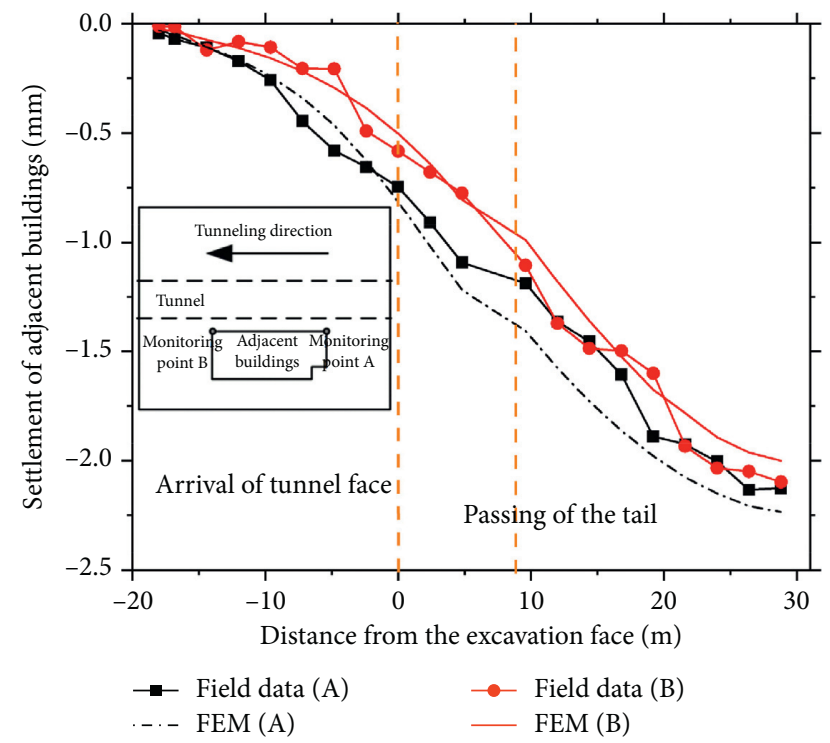

Figure 11: Comparison of settlement simulation and total station monitoring results of adjacent buildings.

$1 \mathrm{~mm}$ due to excavation unloading. When the shield passes through the two measuring points, the friction between the shield shell and the surrounding soil produces a shear force, resulting in a settlement value of nearly $0.4 \mathrm{~mm}$. As the shield tail comes out, a "tail void" between the pipe and the soil is created, resulting in a settlement value of $0.6 \mathrm{~mm}$ on the surface. Finally, the shield is far away from the two measuring points, and the soil is subject to long-term consolidation settlement.

6.3. Parametric Study. The shield method is widely used in the construction of urban rail transit system. During the shield tunneling, the adjacent area is inevitably disturbed. The disturbance is mainly caused by the excavation surface support pressure and formation loss. A parameter sensitivity analysis of the support pressure of the excavation face and the grouting pressure at the tail of the shield is carried out. The simulation results of different excavation face support pressure and grouting pressure construction parameters are further analyzed. The support pressure parameters of the excavation face can be obtained by formula (1), and the

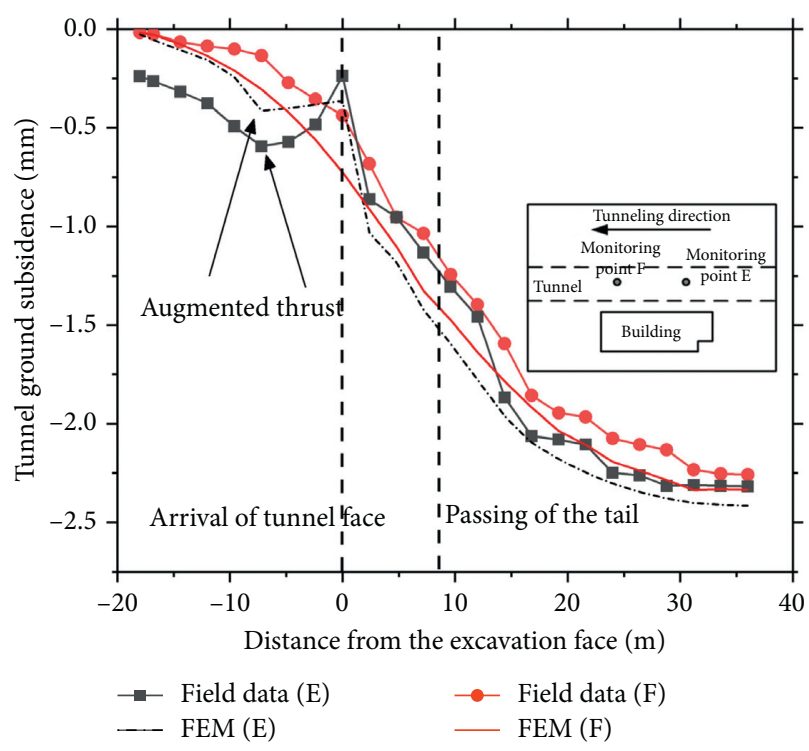

FIgUre 12: Comparison of surface subsidence simulation and total station monitoring results.

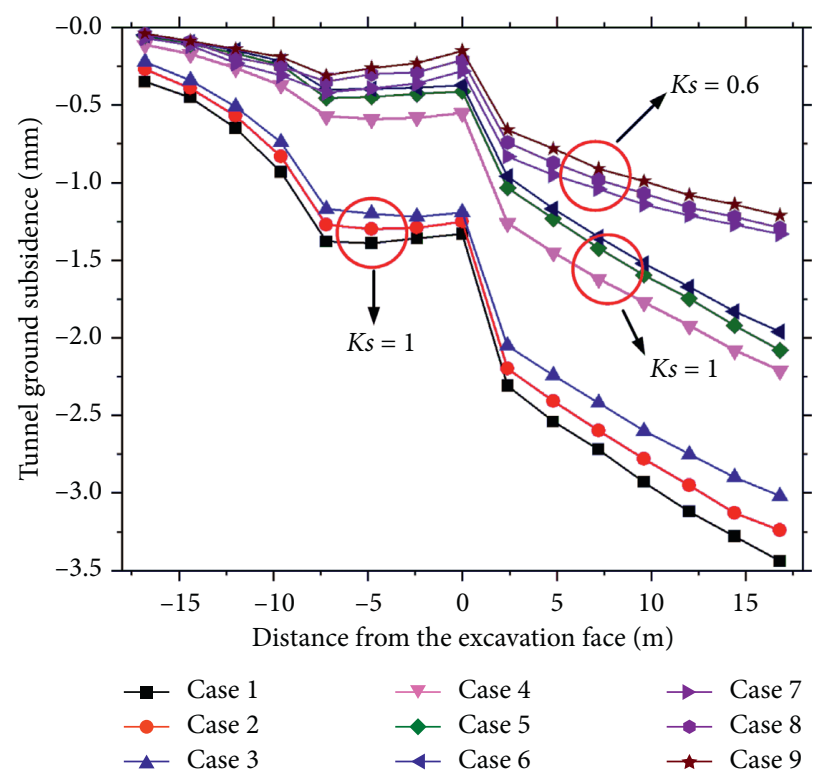

Figure 13: Settlement variation of surface measuring point $\mathrm{E}$ under different working conditions.

support pressure parameters of the excavation face can be obtained by formula (2).

$$
F_{S}=K_{S} \times F_{S 0},
$$

where $K_{s}$ is the adjustment coefficient of support pressure of excavation face. $F_{S O}$ is the initial support pressure of the excavation face. $F_{S}$ is the face support pressure adjusted according to different coefficients.

$$
F_{G}=K_{G} \times F_{G 0},
$$

where $K_{G}$ is the adjustment coefficient of grouting pressure at the tail. $F_{\mathrm{GO}}$ is the initial grouting pressure at the tail. $F_{G}$ is 


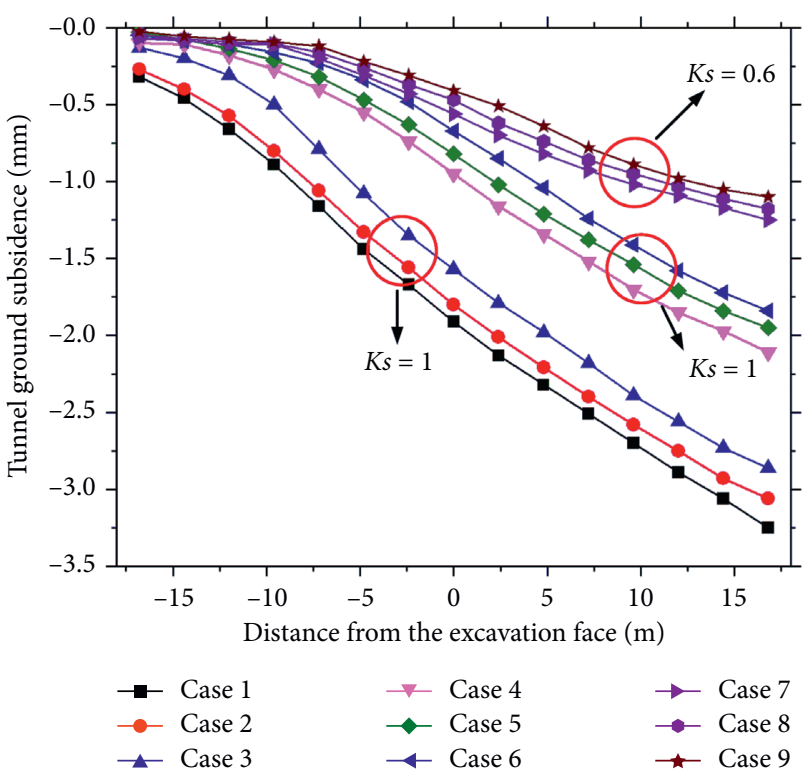

FIgURE 14: Settlement of measuring point $\mathrm{F}$ under different working conditions.

the face grouting pressure adjusted according to different coefficients. The details of the parametric study are summarized in Table 3.

6.3.1. Effect of the Different Parameters on the Surface Settlement. Figure 8 and Figure 11 show the variation curves of surface settlement at different positions above the tunnel axis under the nine different working conditions. In the process of shield tunneling, the surface subsidence increases gradually, and the increased amplitude of settlement increases with the increase of the distance monitoring section. It should be pointed out that there is a small uplift on the surface at a distance of about $-10 \mathrm{~m}$ from the excavation face to the measuring point $\mathrm{E}$. This is because the shield increases the support pressure in the process of tunneling in this section. The maximum surface settlement of the two measuring points within the range of $15 \mathrm{~m}$ from the excavation face is close to $3.5 \mathrm{~mm}$. The effect of changing the support pressure of the excavation face is more obvious than that of changing the grouting pressure. This is because the internal friction angle of the soil in this section is relatively small, the cohesion is relatively large, the self-reliance of the surrounding rock is relatively good, and the stability is relatively high. In conclusion, it can be seen that the excavation face support force can be reasonably increased in the construction to reduce the surface settlement.

6.3.2. Effect of the Different Parameters on the Adjacent Buildings. Figures 12 and 13 show the change curves of settlement at different positions of adjacent buildings under the above nine different working conditions. When the shield passed the monitoring points $\mathrm{A}$ and $\mathrm{B}$, the settlement of adjacent buildings increases gradually, and the increased

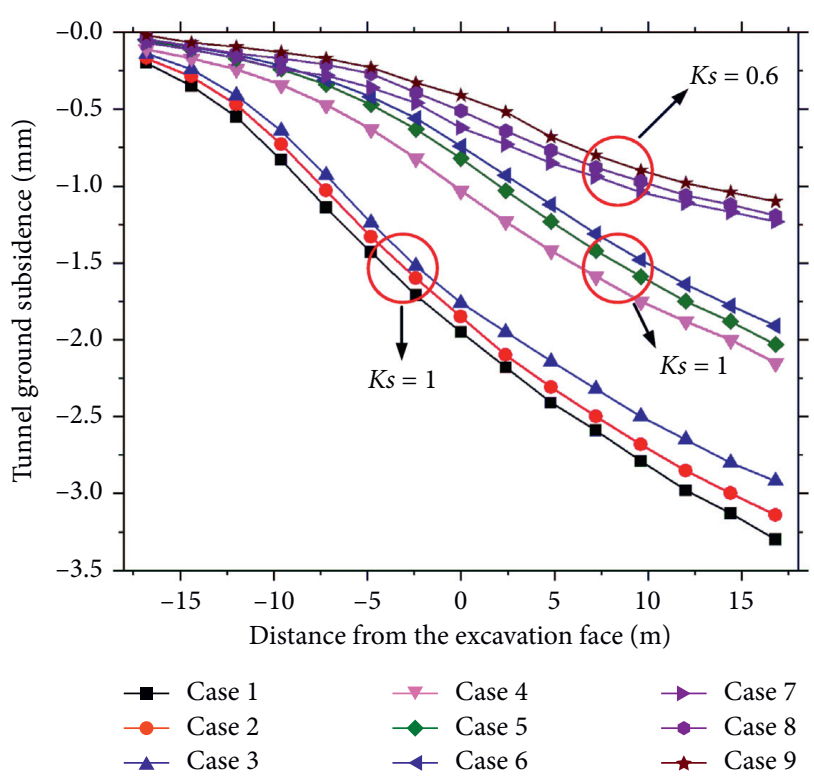

FIgURE 15: Settlement of measuring point A of the adjacent building under different working conditions.

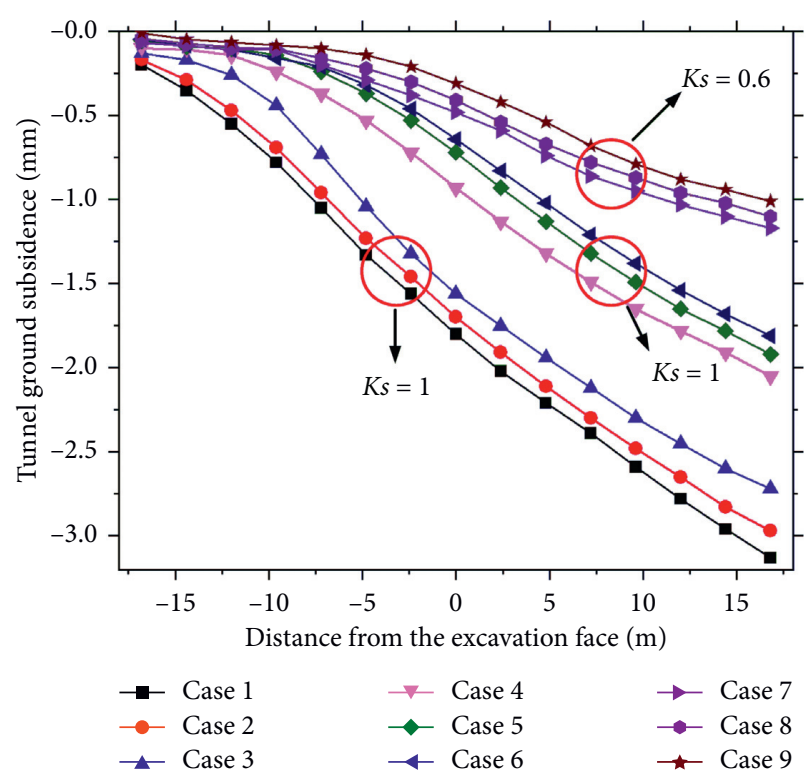

FIgURE 16: Settlement of measuring point $\mathrm{B}$ of the adjacent building under different working conditions.

amplitude of settlement increases with the increase of the distance monitoring section. The maximum settlement within $15 \mathrm{~m}$ from the excavation face to the monitoring point $\mathrm{A}$ and the monitoring point $\mathrm{B}$ is close to $3.5 \mathrm{~mm}$ and $3 \mathrm{~mm}$, respectively. When the support pressure and grouting pressure increase gradually, the settlement value of adjacent buildings decreases gradually. For the settlement reduction of adjacent buildings, increasing the support pressure of the excavation face is more effective than increasing the grouting pressure (Figures 14-16. ). 


\section{Conclusions}

In this paper, through the numerical simulation experiment, it is found that increasing the support force of the shield excavation face can effectively reduce the settlement of the surface and adjacent buildings and guide the construction of a subway section. Through numerical simulation experiment, it is found that increasing the supporting force of shield excavation face can effectively reduce the settlement of the ground and adjacent buildings. Numerical simulation of different construction parameters of grouting pressure and support force of excavation face is carried out. The following conclusions can be drawn:

(1) According to the layout principle and matters needing attention in the engineering site, the layout scheme of the wireless measuring point is made. The results show that the monitoring data of the WSN is consistent with the one of traditional monitoring methods. Compared with traditional monitoring methods, wireless sensing technology shows the advantage of real-time dynamic monitoring in the application of practical engineering.

(2) Shield tunneling has an obvious influence on surface settlement. It mainly makes an impact at the excavation face near the stage and the shield-tail crossing stage. There is a slight uplift on the surface before the shield reaches the measuring point. Then, a large settlement occurred caused by the shield machine overbreak.

(3) Increasing the grouting pressure and the support pressure of the excavation face can reduce the settlement of the surface and adjacent buildings. Besides, increasing the support force of the shield face can effectively control the settlement of surface and adjacent buildings.

\section{Data Availability}

The data supporting the findings of this study are available within the article.

\section{Conflicts of Interest}

The authors declare that they have no conflicts of interest.

\section{Acknowledgments}

This research was conducted with funding provided by the Shandong Natural Science Foundation (Grant no. ZR2020KE031), the National Science Foundation of China (Grant no. 51808150), and the Guangdong Natural Science Foundation (Grant no. 2018A030313132).

\section{References}

[1] C. Liu, Z. Zhang, and R. A. Regueiro, "Pile and pile group response to tunnelling using a large diameter slurry shield case study in Shanghai," Computers and Geotechnics, vol. 59, pp. 21-43, 2014.
[2] C. Liu, L. Pan, F. Wang et al., "Three-dimensional discrete element analysis on tunnel face instability in cobbles using ellipsoidal particles," Materials, vol. 12, no. 20, 2019.

[3] C. Liu, Z. X. Zhang, C. Y. Kwok, H. Q. Jiang, and L. Teng, "Ground responses to tunneling in soft soil using the URUP method," Journal of Geotechnical and Geoenvironmental Engineering, vol. 143, no. 7, 2017.

[4] Z. X. Zhang, C. Liu, and X. Huang, "Numerical analysis of volume loss caused by tunnel face instability in soft soils," Environmental Earth Sciences, vol. 76, no. 16, pp. 563.1-563.19, 2017.

[5] H.-W. Huang and D.-M. Zhang, "Resilience analysis of shield tunnel lining under extreme surcharge: characterization and field application," Tunnelling and Underground Space Technology, vol. 51, pp. 301-312, 2016.

[6] Y. Sun, Y.-S. Xu, S.-L. Shen, and W.-J. Sun, "Field performance of underground structures during shield tunnel construction," Tunnelling and Underground Space Technology, vol. 28, pp. 272-277, 2012.

[7] Y. Li, D. Zhang, Q. Fang, and J. Wang, "Study on safety control technology of upper building crossed by shallow metro tunnel," Tumu Gongcheng Xuebao/China Civil Engineering Journal, vol. 48, pp. 266-269, 2015.

[8] C. Yoo and J.-H. Kim, "A web-based tunneling-induced building/utility damage assessment system: TURISK," Tunnelling and Underground Space Technology, vol. 18, no. 5, pp. 497-511, 2003.

[9] A. Mirhabibi and A. Soroush, "Effects of surface buildings on twin tunnelling-induced ground settlements," Tunnelling and Underground Space Technology, vol. 29, pp. 40-51, 2012.

[10] H. Mroueh and I. Shahrour, "A full 3-D finite element analysis of tunneling-adjacent structures interaction," Computers and Geotechnics, vol. 30, no. 3, pp. 245-253, 2003.

[11] A. Hada, K. Soga, R. Liu, and I. J. Wassell, "Lagrangian heuristic method for the wireless sensor network design problem in railway structural health monitoring," Mechanical Systems and Signal Processing, vol. 28, pp. 20-35, 2012.

[12] J. Zhou, H. Xiao, W. Jiang, W. Bai, and G. Liu, "Automatic subway tunnel displacement monitoring using robotic total station," Measurement, vol. 151, p. 107251, 2019.

[13] E. G. Straser, A. S. Kiremidjian, T. H. Meng, and L. Redlefsen, "Modular, wireless network platform for monitoring structures," Computer Standards \& Interfaces, vol. 21, no. 2, p. 117, 1999.

[14] J. A. Rice and B. F. Spencer, "Structural health monitoring sensor development for the imote2 platform," Sensors and Smart Structures Technologies for Civil, Mechanical, and Aerospace Systems, vol. 2008, Article ID 776695, 2008.

[15] C. Ayyildiz, H. E. Erdem, T. Dirikgil et al., "Structure health monitoring using wireless sensor networks on structural elements," Ad Hoc Networks, vol. 82, pp. 68-76, 2019.

[16] F. Wang, H. Huang, B. He, Y. Wu, H. Shao, and H. Wu, Wireless Sensing on Shield Tunnels in Shanghai, Springer, Berlin, Germany, 2016.

[17] P. J. Bennett, Y. Kobayashi, K. Soga, and P. Wright, "Wireless sensor network for monitoring transport tunnels," Proceedings of the Institution of Civil Engineers - Geotechnical Engineering, vol. 163, no. 3, pp. 147-156, 2010.

[18] P. J. Bennett, K. Soga, I. Wassell et al., "Wireless sensor networks for underground railway applications: case studies in Prague and London," Smart Structures \& Systems, vol. 6, no. 5-6, pp. 619-639, 2010.

[19] GB 50652-2011, Chinese Code. Code for Risk Management of Underground Work in Urban Rail Transit, GB 50652-2011, 2011. 